\title{
Gefitinib-Induced Interstitial Lung Disease in Korean Lung Cancer Patients
}

\section{Seung-Hoon Beom, MD ${ }^{1}$ \\ Dong-Wan Kim, MD, $\mathrm{PhD}{ }^{1,2}$ \\ Sung Hoon Sim, MD ${ }^{1}$ \\ Bhumsuk Keam, MD1,2 \\ Jin Hyun Park, MD ${ }^{1}$ \\ Jeong-Ok Lee, $M D^{1}$ \\ Tae Min Kim, MD, $\mathrm{PhD}{ }^{1,2}$ \\ Se-Hoon Lee, MD, PhD ${ }^{1,2}$ \\ Dae Seog Heo, MD, PhD', 2}

${ }^{1}$ Department of Internal Medicine,

Seoul National University Hospital, Seoul,

${ }^{2}$ Cancer Research Institute,

Seoul National University

College of Medicine, Seoul, Korea

Correspondence: Dong-Wan Kim, MD, PhD

Department of Internal Medicine,

Seoul National University College of Medicine,

101 Daehak-ro, Jongno-gu, Seoul 03080, Korea

Tel: 82-2-2072-2995

Fax: 82-2-764-2199

E-mail: kimdw@snu.ac.kr

Received September 22, 2014

Accepted December 9, 2014

Published Online March 3, 2015

\begin{abstract}
Purpose
Interstitial lung disease (ILD) is a serious adverse effect of gefitinib. We examined the incidence and clinical characteristics of drug-induced ILD in Korean non-small cell lung carcinoma patients treated with gefitinib.
\end{abstract}

\section{Materials and Methods}

A retrospective cohort study was performed in non-small cell lung cancer (NSCLC) patients who started gefitinib treatment at Seoul National University Hospital from January 2002 through December 2011. Patients who developed new abnormal radiologic findings with respiratory symptoms after gefitinib treatment were defined as having possible adverse pulmonary reactions. The patients' medical records were reviewed independently by investigators to identify the causes of pulmonary toxicities.

\section{Results}

Among the 1,114 patients evaluated, 128 patients (11.5\%) developed pulmonary adverse reactions after taking gefitinib. An infectious complication occurred in 98 patients $(8.8 \%)$ and 15 patients (1.3\%) developed ILD. Nine of the 15 patients $(60.0 \%)$ with gefitinib-induced ILD experienced a fatal clinical course that met either the Common Terminology Criteria for Adverse Events grade $4(n=3)$ or grade $5(n=6)$. In the multivariate analysis, a lower serum albumin level $(\leq 3.0 \mathrm{~g} / \mathrm{dL})$ at baseline was significantly associated with the development of gefitinib-induced ILD (odds ratio, 3.91; 95\% confidence interval, 1.20 to 12.71).

\section{Conclusion}

The incidence of gefitinib-induced ILD in Korean NSCLC patients was similar to that reported worldwide, but lower than values reported for Japanese population. ILD was usually a lifethreatening adverse effect of gefitinib, and the development of ILD was significantly associated with a lower baseline serum albumin level.

\section{Key words}

Gefitinib, Interstitial lung diseases, Lung injury,

Drug-related side effects and adverse reactions, Lung neoplasms

\section{Introduction}

Epidermal growth factor receptor (EGFR) tyrosine kinase inhibitors are well-established treatments for advanced nonsmall cell lung cancer (NSCLC) in many countries. They are generally well tolerated and not associated with the side effects typical of cytotoxic chemotherapy.

Gefitinib (Iressa, AstraZeneca, London, UK) is an orally administered, reversible tyrosine kinase inhibitor of EGFR.
In 2002, it was approved for the treatment of inoperable or recurrent NSCLC based on the results of two large-scale multicenter phase II studies that yielded favorable responses and low toxicities [1]. The Iressa Pan-Asia Study (IPASS) found that gefitinib produced longer progression-free survival compared to carboplatin plus paclitaxel in patients with advanced pulmonary adenocarcinoma harboring EGFR mutations [2]. A more recent phase III trial, conducted in metastatic NSCLC patients with mutated EGFR, confirmed these findings [3]. 
Common adverse events associated with gefitinib treatment are diarrhea, skin rashes, and nausea, but most of these are mild in severity and manageable [2,3]. However, since the first report of gefitinib-induced interstitial lung disease (ILD) from Japan [4], ILD associated with molecularly targeted agents has drawn considerable attention. The incidence of ILD during gefitinib treatment was not infrequent and varied among ethnicities. The incidence of gefitinibinduced ILD was approximately $1 \%$ in worldwide populations [1], while the frequency of ILD in the Japanese series was reported to be much higher than that in the rest of the world [5]. The incidence in other Asian populations, besides Japanese, remains uncertain. In Korean patients, several small prospective studies reported a high incidence (1.3\%$3.7 \%$ ) of ILD during gefitinib treatment [6-8].

Gefitinib-induced ILD is often life-threatening; its mortality is approximately $30 \%-40 \%$ [9]. However, investigation of predictive and prognostic factors for gefitinib-induced ILD is limited. Even less is known about the mechanisms of developing ILD.

In this study, we estimate the incidence of gefitinibinduced ILD in a large Korean population and describe the major clinical findings. Furthermore, we evaluate possible risk and prognostic factors for gefitinib-induced ILD.

\section{Materials and Methods}

\section{Study populations}

A retrospective cohort study was performed with histology proven NSCLC patients who were treated with gefitinib at Seoul National University Hospital from January 2002 through December 2011 [10]. Patient clinical data, including medical records, radiographic findings and laboratory results were reviewed. This study protocol was approved by the Institutional Review Board (IRB) of the Seoul National University Hospital (IRB protocol number: H 1308-047-511).

\section{Clinical data collection}

The following demographic data were abstracted: age, sex, comorbidities, smoking history, Eastern Cooperative Oncology Group (ECOG) performance status, histologic type, previous anticancer treatment and concurrent pulmonary disease (e.g., pulmonary emphysema or interstitial pneumonitis). Adverse events from gefitinib treatment were evaluated using the Common Terminology Criteria for Adverse Events (CTCAE) from the National Cancer Institute ver. 4.0 and a fatal adverse event was defined as being CTCAE grade 4 or grade 5 . Treatment response to gefitinib was assessed according to the criteria of the Response Evaluation Criteria in Solid Tumors (RECIST) ver. 1.1. We classified a patient who had partial or complete response as a responder. Laboratory results, including complete blood cell and differential counts, chemistry tests, and oxyhemoglobin saturation measured by pulse oximetry $\left(\mathrm{SpO}_{2}\right)$ performed when gefitinib treatment began and when ILD occurred were collected. Overall survival was calculated from the initiation of gefitinib treatment to the date of death or last follow-up.

\section{Confirmation of adverse pulmonary reaction and gefi- tinib-induced ILD}

New abnormal radiologic findings with respiratory symptoms after gefitinib treatment were defined as possible adverse pulmonary reactions. To identify the cause of an adverse pulmonary reaction, two of the investigators (S.-H.B and S.H.S) reviewed the data independently. If their opinions differed regarding the cause of an adverse pulmonary reaction, another investigator (D.-W.K.) made the decision. Pulmonary infiltrates identified as lung cancer progression were excluded from this evaluation. Adverse pulmonary reactions were classified as non-infectious and infectious complications; the causes of non-infectious complications were categorized using published classifications [11,12]. The diagnosis of gefitinib-induced ILD was based on published, generally accepted clinical criteria $[9,13]$. In brief, for the diagnosis of ILD, four specific findings were required: (1) progressive dyspnea with or without cough or fever, (2) lack of evidence of infection, (3) radiologic findings consistent with druginduced ILD (i.e., bilateral, diffuse, or patchy interstitial and/or alveolar opacifications without evidence of marked progression of underlying lung cancer), and (4) consistent pathologic findings, if available.

\section{Statistical analysis}

Categorical clinical variables were compared using a chisquared test or Fisher exact test. Continuous variables were compared using an independent unpaired $t$ test or the MannWhitney $U$ test if the variables were not normally distributed. Univariate analysis was performed to evaluate associations between the outcomes of gefitinib-induced ILD and patient characteristics. Predictive factors for gefitinibinduced ILD were assessed by multivariate logistic regression models. Variables with a p-value in the univariate analysis of less than 0.2 were selected for the multivariate analysis. Overall survival was assessed by Kaplan-Meier method after onset of ILD in different patient groups. Two-sided null hypotheses of no difference were rejected if $p$-values were 


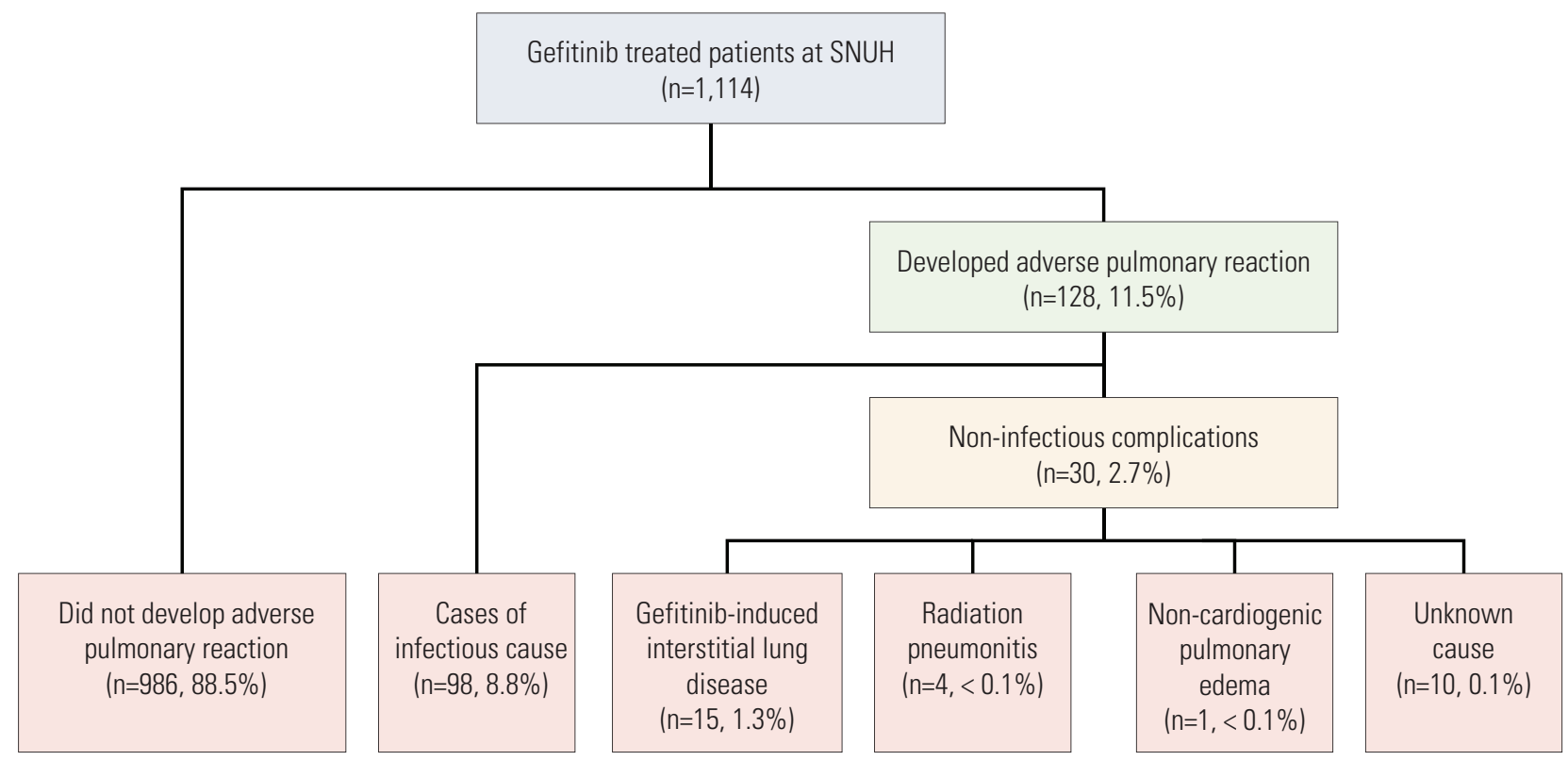

Fig. 1. Outline of patient recruitment and distribution of adverse pulmonary reactions. SNUH, Seoul National University Hospital.

less than 0.05 , or, equivalently, if the $95 \%$ confidence intervals (CIs) of risk point estimates excluded 1. All statistical analyses were performed with SPSS ver. 21.0 (IBM SPSS Statistics, IBM Co., Armonk, NY).

\section{Results}

\section{Incidence of adverse pulmonary reaction and gefitinib- induced ILD}

The medical records of the 1,114 patients who received gefitinib from January 2002 through December 2011 were reviewed and abstracted (Fig. 1). Among these patients, 128 patients $(11.5 \%)$ developed symptomatic pulmonary infiltrates after treatment initiation. All patients were treated with gefitinib monotherapy. An infectious pulmonary complication occurred in 98 patients $(8.8 \%)$, and 30 patients $(2.7 \%)$ experienced a non-infectious pulmonary complication. Fifteen patients $(1.3 \%)$ with gefitinib-induced ILD were identified.

\section{Risk factors for gefitinib-induced ILD}

In multivariate analysis, only a lower serum albumin level was significantly associated with the development of gefi- tinib-induced ILD after adjusting for sex, hypertension and coincidence of ILD (odds ratio, 3.91; 95\% CI, 1.20 to 12.71) (Tables 1 and 2). The association between the coincidence of ILD before treatment and the development of gefitinibinduced ILD was not significant statistically. The model fit was confirmed with the Hosmer-Lemeshow goodness of fitness test $(\mathrm{p}=0.419)$.

\section{Clinical characteristics of gefitinib-induced ILD}

Clinical and laboratory findings of gefitinib-induced ILD are summarized in Table 3. The median time interval from the start of gefitinib administration to onset of ILD was 29.0 days (range, 3 to 1,953 days) (Fig. 2). In 12 patients (80.0\%), ILD occurred during the first 8 weeks of gefitinib treatment. Gefitinib was used as second or later line treatment. In three patients (20.0\%), the computed tomography (CT) findings at the time of ILD diagnosis revealed combined lung cancer progression. ILD developed in one patient $(6.7 \%)$ who responded to gefitinib treatment. The most common clinical presentation of gefitinib-induced ILD was dyspnea (100\%), followed by cough $(60.0 \%)$. Two patients $(13.3 \%)$ presented with fever at the onset of ILD. Severe hypoxemia was found and the mean $\mathrm{SpO}_{2}$ was $80.47 \%$ on room air. Leukocytosis and elevated level of $\mathrm{C}$-reactive protein $(\mathrm{CRP})$ were common; mean leukocytes count was $13.90 \times 10^{3} / \mu \mathrm{L}$ and mean CRP level was $12.01 \mathrm{mg} / \mathrm{dL}$. No patient presented with eosinophilia at the time of ILD diagnosis. The mean albumin level 
Table 1. Univariate analysis of risk factors for gefitinib-induced interstitial lung disease (ILD)

\begin{tabular}{|c|c|c|c|c|c|}
\hline \multirow{2}{*}{ Variable } & \multirow{2}{*}{ Total $(n=1,114)$} & \multicolumn{4}{|c|}{ Gefitinib-induced ILD } \\
\hline & & No $(n=1,099)$ & Yes $(n=15)$ & OR $(95 \% \mathrm{CI})$ & p-value \\
\hline Mean age (yr) & $60.34(25-91)$ & $60.34 \pm 11.42$ & $60.69 \pm 12.01$ & $1.00(0.96-1.05)$ & 0.906 \\
\hline \multicolumn{6}{|l|}{ Sex } \\
\hline Male & $514(46.1)$ & $510(46.4)$ & $4(26.7)$ & 1 & $0.139^{a)}$ \\
\hline Female & $600(53.9)$ & $589(53.6)$ & $11(73.3)$ & $2.38(0.75-7.52)$ & \\
\hline \multicolumn{6}{|l|}{ History of smoking } \\
\hline No & $643(57.7)$ & $632(57.5)$ & $11(73.3)$ & 1 & 0.239 \\
\hline Yes & $463(41.6)$ & $459(41.7)$ & $4(26.7)$ & $0.50(0.16-1.58)$ & \\
\hline Unknown & $8(0.7)$ & $8(0.7)$ & 0 & & \\
\hline \multicolumn{6}{|l|}{ ECOG PS } \\
\hline $0-1$ & $733(65.8)$ & $723(65.8)$ & $10(66.7)$ & 1 & 0.978 \\
\hline $2-4$ & $372(33.4)$ & $367(33.4)$ & $5(33.3)$ & $0.99(0.33-2.90)$ & \\
\hline Unknown & $9(0.8)$ & $9(0.8)$ & 0 & & \\
\hline \multicolumn{6}{|l|}{ Comorbidities } \\
\hline \multicolumn{6}{|l|}{ Diabetes } \\
\hline No & $941(84.5)$ & $927(84.3)$ & $14(93.3)$ & 1 & 0.409 \\
\hline Yes & $157(14.1)$ & $156(14.2)$ & $1(6.7)$ & $0.42(0.06-3.25)$ & \\
\hline Unknown & $16(1.4)$ & $16(1.5)$ & 0 & & \\
\hline \multicolumn{6}{|l|}{ Hypertension } \\
\hline No & $742(66.6)$ & $729(66.3)$ & $13(86.7)$ & 1 & $0.133^{\mathrm{a})}$ \\
\hline Yes & 355 (31.9) & $353(32.1)$ & $2(13.3)$ & $0.32(0.07-1.42)$ & \\
\hline Unknown & $17(1.5)$ & $17(1.5)$ & 0 & & \\
\hline \multicolumn{6}{|c|}{ History of tuberculosis } \\
\hline No & $896(80.4)$ & $884(80.4)$ & $12(80.0)$ & 1 & 0.866 \\
\hline Yes & $201(18.0)$ & $198(18.0)$ & $3(20.0)$ & $1.12(0.31-3.99)$ & \\
\hline Unknown & $17(1.5)$ & $17(1.5)$ & 0 & & \\
\hline \multicolumn{6}{|c|}{ Interstitial lung disease } \\
\hline No & $1,096(98.4)$ & $1,082(98.5)$ & $14(93.3)$ & 1 & $0.155^{\mathrm{a})}$ \\
\hline Yes & $18(1.6)$ & $17(1.5)$ & $1(6.7)$ & $4.55(0.57-36.56)$ & \\
\hline \multicolumn{6}{|l|}{ Emphysema } \\
\hline No & $907(81.4)$ & $895(81.4)$ & $12(80.0)$ & 1 & 0.887 \\
\hline Yes & 207 (18.6) & $204(18.6)$ & $3(20.0)$ & $1.10(0.31-3.92)$ & \\
\hline \multicolumn{6}{|l|}{ Histological type } \\
\hline Adenocarcinoma & $797(71.5)$ & 787 (71.6) & $10(66.7)$ & 1 & 0.674 \\
\hline Others & $317(28.5)$ & $312(28.4)$ & $5(33.3)$ & $1.26(0.43-3.72)$ & \\
\hline \multicolumn{6}{|l|}{ Previous treatment } \\
\hline \multicolumn{6}{|l|}{ Chest surgery } \\
\hline No & $905(81.2)$ & $894(81.3)$ & $11(73.3)$ & 1 & 0.434 \\
\hline Yes & $209(18.8)$ & $205(18.7)$ & $4(26.7)$ & $1.58(0.50-5.03)$ & \\
\hline \multicolumn{6}{|l|}{ Thoracic radiotherapy } \\
\hline No & $894(80.3)$ & $881(80.2)$ & $13(86.7)$ & 1 & 0.534 \\
\hline Yes & $220(19.7)$ & $218(19.8)$ & $2(13.3)$ & $0.62(0.14-2.78)$ & \\
\hline \multicolumn{6}{|l|}{ Chemotherapy } \\
\hline No & $169(15.2)$ & $169(15.2)$ & 0 & 1 & 0.995 \\
\hline Yes & $945(84.8)$ & $930(84.6)$ & $15(100)$ & 0.00 & \\
\hline \multicolumn{6}{|c|}{ Laboratory results at baseline } \\
\hline Hemoglobin $(\mathrm{g} / \mathrm{dL})$ & $11.84 \pm 1.74$ & $11.85 \pm 1.74$ & $11.02 \pm 1.37$ & & \\
\hline$<10$ & $147(13.2)$ & $144(13.1)$ & $3(20.0)$ & 1 & 0.438 \\
\hline$\geq 10$ & $967(86.8)$ & $955(86.9)$ & $12(80.0)$ & $0.60(0.17-2.16)$ & \\
\hline
\end{tabular}


Table 1. Continued

\begin{tabular}{|c|c|c|c|c|c|}
\hline \multirow{2}{*}{ Variable } & \multirow{2}{*}{ Total $(n=1,114)$} & \multicolumn{4}{|c|}{ Gefitinib-induced ILD } \\
\hline & & No $(n=1,099)$ & Yes $(n=15)$ & OR $(95 \% \mathrm{CI})$ & p-value \\
\hline Leukocytes $\left(\times 10^{3} / \mu \mathrm{L}\right)$ & $7.71 \pm 3.69$ & $7.70 \pm 3.67$ & $8.38 \pm 4.94$ & & \\
\hline$\leq 10$ & $915(82.1)$ & $904(82.3)$ & $11(73.3)$ & 1 & 0.375 \\
\hline$>10$ & 199 (17.9) & 195 (17.7) & $4(26.7)$ & $1.69(0.53-5.35)$ & \\
\hline Creatinine $(\mathrm{mg} / \mathrm{dL})$ & $0.94 \pm 0.35$ & $0.94 \pm 0.35$ & $0.78 \pm 0.17$ & & \\
\hline$\leq 1.3$ & 1,061 (95.2) & $1,046(95.2)$ & $15(100)$ & 1 & 0.998 \\
\hline$>1.3$ & $53(4.8)$ & $53(4.8)$ & 0 & 0.00 & \\
\hline AST (IU /L) & $24.77 \pm 15.43$ & $24.80 \pm 15.51$ & $22.27 \pm 6.46$ & & \\
\hline$\leq 40$ & $1,029(92.4)$ & $1,014(92.3)$ & $15(100)$ & 1 & 0.997 \\
\hline$>40$ & $85(7.6)$ & $85(7.7)$ & 0 & 0.00 & \\
\hline ALT (IU/L) & $24.71 \pm 31.49$ & $24.84 \pm 31.67$ & $15.13 \pm 9.07$ & & \\
\hline$\leq 40$ & $987(88.6)$ & $972(88.4)$ & $15(100)$ & 1 & 0.996 \\
\hline$>40$ & $127(11.4)$ & $127(11.6)$ & 0 & 0.00 & \\
\hline Albumin (g/dL) & $3.84 \pm 0.52$ & $3.85 \pm 0.52$ & $3.51 \pm 0.58$ & & \\
\hline$>3.0$ & $1,005(90.2)$ & $994(90.4)$ & $11(73.3)$ & 1 & $0.037^{\mathrm{a})}$ \\
\hline$\leq 3.0$ & $109(9.8)$ & $105(9.6)$ & $4(26.7)$ & $3.44(1.08-11.00)$ & \\
\hline
\end{tabular}

Values are presented as mean \pm standard deviation or number (\%) unless otherwise stated. OR, odds ratio; CI, confidence interval; ECOS PS, Eastern Cooperative Oncology Group performance status; AST, aspartate transaminase; ALT, alanine transaminase. ${ }^{\text {a)}}$ Data used for multivariate analysis of risk factors for gefitinib-induced ILD.

Table 2. Multivariate analysis of risk factors for gefitinib-induced interstitial lung disease

\begin{tabular}{lccc} 
Variable & Adjusted odds ratio & 95\% Confidence interval & p-value \\
Sex (female vs. male) & 2.77 & $0.85-9.04$ & 0.092 \\
Hypertension (yes vs. no) & 0.29 & $0.06-1.33$ & 0.111 \\
\hline Interstitial lung disease (yes vs. no) & 8.33 & $0.95-73.37$ & 0.056 \\
Albumin $(\leq 3.0 \mathrm{~g} / \mathrm{dL}$ vs. $>3.0 \mathrm{~g} / \mathrm{dL})$ & 3.91 & $1.20-12.71$ & 0.024 \\
\hline
\end{tabular}

at the time of ILD development was $3.03 \mathrm{~g} / \mathrm{dL}$. In two patients $(13.3 \%)$, nosocomial pneumonia occurred during treatment of ILD.

\section{Treatment and outcomes of gefitinib-induced ILD}

Treatment and outcomes of gefitinib-induced ILD are summarized in Table 3. Gefitinib was immediately discontinued in all patients when ILD was clinically suspected. None of these patients were rechallenged with gefitinib. Two patients received chemotherapy after ILD improved. One patient underwent pemetrexed treatment and the other received erlotinib. The patient treated with erlotinib began medication 3 months after development of gefitinib-induced ILD. She received erlotinib treatment for 1 month but had to stop the medication due to newly appeared multifocal patch groundglass opacities in both lungs on chest CT. In microbiologic examinations, sputum pneumocystis jirovecii polymerase chain reaction was positive, and the patient was treated with intravenous sulfamethoxazole, trimethoprim, and steroid. After pneumocystis pneumonia developed, she was transferred to another hospital near her hometown for hospice care because of worsened general condition.

Twelve patients $(80.0 \%)$ received systemic corticosteroids for gefitinib-induced ILD. The mean dose was equivalent to $0.87 \mathrm{mg} / \mathrm{kg} /$ day methylprednisolone initially and was gradually tapered. Among the 15 patients with gefitinib-induced ILD, nine patients $(60.0 \%)$ had a fatal clinical course and six patients $(40.0 \%)$ died directly from ILD. The other three patients $(20.0 \%)$ recovered from the potentially fatal ILD condition after stopping the medication or steroid treatment. However, nosocomial respiratory superinfection developed in two patients and uncontrolled infection caused their death. One patient expired from sudden cardiac arrest of 


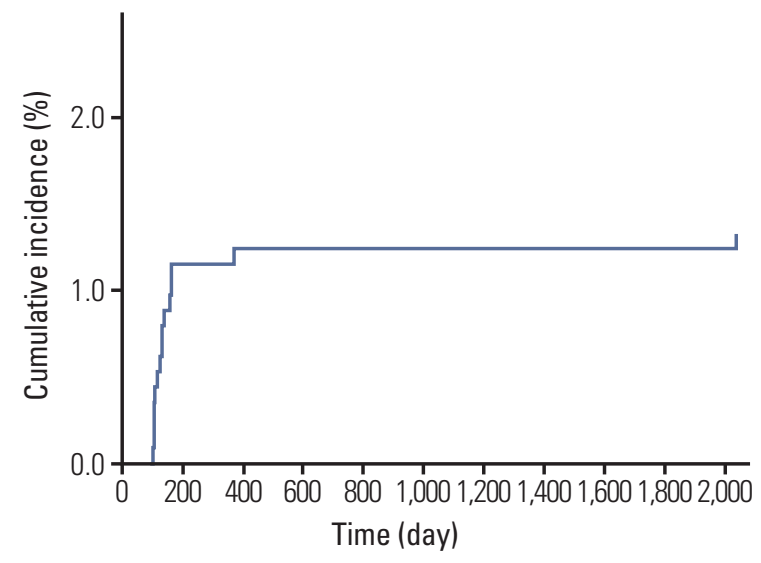

Fig. 2. Cumulative incidence of gefitinib-induced interstitial lung disease.

unknown cause when he under observation in a general ward as gefitinib-induced ILD improving after steroid treatment. The median survival time from onset of ILD was 7.10 weeks.

We compared the clinical and laboratory variables of the fatal and non-fatal cases of ILD and found that patients in the fatal group developed ILD after a shorter median length of gefitinib administration and had lower mean $\mathrm{SpO}_{2}$ and lower albumin level at the time of ILD development than did the non-fatal group (Table 3). However, the fatal and nonfatal groups did not differ significantly in underlying comorbidities, pulmonary disease, types of previous cancer treatment, time interval from onset of ILD to cessation of gefitinib or administration of corticosteroids, and methylprednisolone dosage.

\section{Discussion}

Gefitinib is recognized as an acceptably safe oral agent, given that the most common toxicities associated with its use are mild and self-limiting, such as skin toxicities and diarrhea [1]. However, the development of ILD during gefitinib treatment is a drug-related toxicity that sometimes has serious consequences. In 2003, an Food and Drug Administration (FDA) analysis of 50,000 patients who received gefitinib reported a $1 \%$ worldwide incidence of ILD [1]. Notably, the incidence of ILD in Japanese populations was reported to range between $2.4 \%$ and $5.4 \%$ in clinical trials [9,13-18]. In other Asian studies, the incidence of ILD also exceeds the global incidence; in Taiwanese patients, it was reported at $2.3 \%$ [19]. However, the incidence of ILD in our study was $1.3 \%$, similar to values reported worldwide. This is much lower than reported in other Asian populations, including studies of Japanese and Taiwanese patients (Table 4).

Risk factors for ILD have been identified in several Japanese studies (Table 4), but the findings from the reported studies are inconsistent. In the present study, we attempted to identify risk factors for ILD in gefitinib-treated NSCLC patients by collecting all possible risk factors, including laboratory results and clinical factors that were evaluated in previous studies. Unlike the previous results, a lower serum albumin level at the time of gefitinib treatment initiation was the only risk factor for developing gefitinib-induced ILD. A smaller Japanese study evaluated the association between ILD and several laboratory values including albumin level, but did not find a significant association [16].

The mechanism by which gefitinib may cause ILD is unclear. However, decreased EGFR phosphorylation resulting in a decrease in regenerative epithelial proliferation could augment pulmonary fibrosis [20]. We found that a lower serum albumin level might be an important surrogate marker for predicting gefitinib-induced ILD. Notably, the albumin level at the time of ILD development decreased compared to that before gefitinib administration (from a mean of 3.51 to $3.03 \mathrm{~g} / \mathrm{dL}$ ). A similar phenomenon occurs with methotrexate therapy. Methotrexate is a commonly prescribed antineoplastic agent and an immune modulating compound. Its pulmonary toxicities are well described. Hypoalbuminemia is a predisposing factor for methotrexateinduced pulmonary toxicity (either before or during therapy) [21]. It has been hypothesized that a lower degree of protein binding of methotrexate and higher levels of free methotrexate resulting from hypoalbuminemia could enhance druginduced pulmonary toxicity in methotrexate-treated patients [21]. Gefitinib is also primarily bound to plasma proteins including human serum albumin $(90 \%)$ and alpha-1 acid glycoprotein $(78 \%)$ [22]. Similarly, methotrexate is bound to plasma protein $(\sim 50 \%)$. Ter Heine et al. [23] reported a case of fatal ILD associated with another EGFR tyrosine kinase inhibitor erlotinib, with high erlotinib and metabolite plasma levels, and suggested that high drug and metabolite levels result in severe adverse pulmonary reactions. With these drugs, a lower albumin level might lead to higher levels of free gefitinib and enhance pulmonary toxicity. In a study of another target agent, monoclonal antibodies, low albumin level was identified as a risk factor for developing adverse pulmonary reactions in cancer patients [12]. However, the cause for gefitinib-associated ILD is multifactorial and it is difficult to demonstrate causation between hypoalbuminemia and the development of gefitinib-induced ILD from the results in our study. In addition, hypoalbuminemia in itself 
Table 3. Clinical features and outcomes of gefitinib-induced interstitial lung disease (ILD)

\begin{tabular}{|c|c|c|c|c|}
\hline Variable & Total $(\mathrm{n}=\mathbf{1 5})$ & Non-fatal $(n=6)$ & Fatal $(n=9)$ & p-value \\
\hline \multicolumn{5}{|l|}{ Clinical findings } \\
\hline Mean age (yr) & $60.69 \pm 12.01$ & $66.93 \pm 10.60$ & $56.53 \pm 11.55$ & 0.101 \\
\hline Sex (male:female) & 4 (26.7):11 (73.3) & $0(0): 6(100)$ & $4(44.4): 5(55.6)$ & 0.103 \\
\hline Current or ex-smoker & $4(26.7)$ & 0 & $4(44.4)$ & 0.103 \\
\hline ECOG PS $(\geq 2)$ & $5(33.3)$ & $3(50.0)$ & $2(22.2)$ & 0.329 \\
\hline Emphysematous lung & $3(20.0)$ & 0 & $3(33.3)$ & 0.229 \\
\hline \multicolumn{5}{|l|}{ Previous treatment } \\
\hline Chest surgery & $4(26.7)$ & $2(33.3)$ & $2(22.2)$ & $>0.999$ \\
\hline Thoracic radiotherapy & $2(13.3)$ & $1(16.7)$ & $1(11.1)$ & $>0.999$ \\
\hline Chemotherapy & $15(100)$ & $6(100)$ & $9(100)$ & $>0.999$ \\
\hline Combined lung cancer progression & $3(20.0)$ & $1(16.7)$ & $2(22.2)$ & $>0.999$ \\
\hline Responder to gefitinib & $1(6.7)$ & $1(16.7)$ & 0 & 0.400 \\
\hline $\begin{array}{l}\text { Onset of symptoms after gefitinib } \\
\text { therapy, median (range, day) }\end{array}$ & $29.0(3-1,953)$ & $54.0(14-1,953)$ & $10.0(3-56)$ & 0.024 \\
\hline$\leq 8 \mathrm{wk}$ & $12(80.0)$ & $3(50.0)$ & $9(100)$ & 0.044 \\
\hline$>8 \mathrm{wk}$ & $3(20.0)$ & $3(50.0)$ & 0 & \\
\hline \multicolumn{5}{|l|}{ Symptoms } \\
\hline Dyspnea & $15(100)$ & $6(100)$ & $9(100)$ & $>0.999$ \\
\hline Cough & $9(60.0)$ & $4(66.7)$ & $5(55.6)$ & $>0.999$ \\
\hline Chest discomfort & $2(13.3)$ & 0 & $2(22.2)$ & 0.486 \\
\hline Fever $\geq 38.0^{\circ} \mathrm{C}$ & $2(13.3)$ & 0 & $2(22.2)$ & 0.486 \\
\hline $\mathrm{SpO}_{2}(\%)(\mathrm{n}=13)$ & $80.47 \pm 20.32$ & $96.75 \pm 2.06$ & $73.23 \pm 20.65$ & 0.009 \\
\hline \multicolumn{5}{|l|}{ Laboratory findings at the time of ILD onset } \\
\hline Leukocytes $\left(\times 10^{3} / \mu \mathrm{L}\right)$ & $13.90 \pm 8.47$ & $9.08 \pm 2.35$ & $17.12 \pm 9.68$ & 0.070 \\
\hline Eosinophil percentage & $2.52 \pm 2.60$ & $3.05 \pm 2.53$ & $2.17 \pm 2.74$ & 0.539 \\
\hline Hemoglobin $(\mathrm{g} / \mathrm{dL})$ & $10.86 \pm 1.97$ & $11.17 \pm 2.61$ & $10.66 \pm 1.56$ & 0.641 \\
\hline $\mathrm{CRP}(\mathrm{mg} / \mathrm{dL})(\mathrm{n}=13)$ & $12.01 \pm 8.78$ & $7.72 \pm 10.31$ & $13.92 \pm 7.91$ & 0.257 \\
\hline Albumin (g/dL) & $3.03 \pm 0.56$ & $3.55 \pm 0.45$ & $2.69 \pm 0.31$ & 0.001 \\
\hline \multicolumn{5}{|l|}{ Treatment } \\
\hline Cessation of gefitinib treatment & $15(100)$ & $6(100)$ & $9(100)$ & $>0.999$ \\
\hline $\begin{array}{l}\text { Interval from onset of symptoms to } \\
\text { cessation of gefitinib (day) }\end{array}$ & $8.21 \pm 8.12$ & $10.80 \pm 7.66$ & $6.78 \pm 8.44$ & 0.396 \\
\hline Administration of corticosteroids & $12(80.0)$ & $4(66.7)$ & $8(88.9)$ & 0.525 \\
\hline $\begin{array}{l}\text { Methylprednisolone dose } \\
(\mathrm{mg} / \mathrm{kg} / \text { day) at first }\end{array}$ & $0.87 \pm 0.61$ & $0.52 \pm 0.42$ & $1.06 \pm 0.63$ & 0.110 \\
\hline Duration of corticosteroids treatment (day) & $34.08 \pm 34.24$ & $61.50 \pm 45.86$ & $20.38 \pm 17.22$ & 0.170 \\
\hline $\begin{array}{l}\text { Interval from symptom onset to start } \\
\text { of corticosteroids (day) }\end{array}$ & $5.64 \pm 4.38$ & $8.20 \pm 6.02$ & $4.22 \pm 2.59$ & 0.087 \\
\hline Coadministration of antibiotics & $12(80.0)$ & $4(66.7)$ & $8(88.9)$ & 0.220 \\
\hline \multicolumn{5}{|l|}{ Clinical course } \\
\hline ILD-related death & $6(40.0)$ & 0 & $6(66.7)$ & 0.028 \\
\hline Median survival time after ILD onset (wk) & $7.10 \pm 2.93$ & $16.00 \pm 2.12$ & $4.10 \pm 3.58$ & $<0.001$ \\
\hline Subsequent chemotherapy after ILD & & & & 0.177 \\
\hline Cytotoxic chemotherapy & $1(6.7)$ & $1(16.7)$ & 0 & \\
\hline Erlotinib & $1(6.7)$ & $1(16.7)$ & 0 & \\
\hline
\end{tabular}

Values are presented as mean \pm standard deviation or number $(\%)$ unless otherwise stated. ECOG PS, Eastern Cooperative Oncology Group performance status. 
Table 4. Reported incidence, mortality and risk factors of gefitinib-induced interstitial lung disease (ILD) in Japanese [9,1318] and Taiwanese [19] studies

\begin{tabular}{|c|c|c|c|c|c|}
\hline Year & Study group & $\begin{array}{l}\text { No. of } \\
\text { patients }\end{array}$ & $\begin{array}{l}\text { No. cases of } \\
\text { ILD }(\%)\end{array}$ & $\begin{array}{l}\text { No. ILD death } \\
\text { (mortality, \%) }\end{array}$ & Risk factor \\
\hline 2004 & $\begin{array}{l}\text { National Cancer Center, } \\
\text { Japan [14] }\end{array}$ & 112 & $6(5.4)$ & $4(66.7)$ & Preexisting pulmonary fibrosis \\
\hline 2005 & $\begin{array}{l}\text { Okayama Lung Cancer Study } \\
\text { Group [15] }\end{array}$ & 330 & $15(4.5)$ & $8(53.3)$ & $\begin{array}{l}\text { Preexisting pulmonary fibrosis, poor PS, } \\
\text { prior thoracic irradiation }\end{array}$ \\
\hline 2006 & $\begin{array}{l}\text { West Japan Thoracic Oncology } \\
\text { Group [13] }\end{array}$ & 1,976 & $70(3.5)$ & $31(44.3)$ & $\begin{array}{l}\text { Preexisting pulmonary fibrosis, male, } \\
\text { smoking }\end{array}$ \\
\hline 2008 & AstraZeneca [9] & 1,482 & $59(4.0)$ & - (31.6) & $\begin{array}{l}\text { Preexisting chronic ILD, poor PS, smoker, } \\
\text { older age (> 55 years), recent NSCLC } \\
\text { diagnosis, reduced normal lung on } \\
\text { computed tomography scan, concurrent } \\
\text { cardiac disease }\end{array}$ \\
\hline 2009 & $\begin{array}{l}\text { Japan-Multinational Trial } \\
\text { Organization [16] }\end{array}$ & 526 & $17(3.2)$ & $7(41.2)$ & No risk factors found \\
\hline 2010 & $\begin{array}{l}\text { Okayama Lung Cancer Study } \\
\text { Group [17] }\end{array}$ & 330 & $8(2.4)$ & $5(62.5)$ & Preexisting pulmonary fibrosis, poor PS \\
\hline 2013 & $\begin{array}{l}\text { NEJ } 002 \text { and WJTOG } 3405 \\
\text { trials [18] }\end{array}$ & $\begin{array}{c}201 \\
\text { (EGFR mutation } \\
\text { positive) }\end{array}$ & $10(5.0)$ & $2(20.0)$ & Smoking \\
\hline 2013 & Chang et al. [19] & 1,080 & $25(2.3)$ & $10(40.0)$ & Not evaluated \\
\hline 2013 & This study & 1,114 & $15(1.3)$ & $6(40.0)$ & Lower albumin level \\
\hline
\end{tabular}

PS, performance status; NSCLC, non-small cell lung cancer.

is a marker for illness severity and malnutrition, and many confounding clinical factors can influence the development of hypoalbuminemia.

Another possible predisposing factor for gefitinib-induced ILD is ethnic differences in susceptibility to ILD. Notably, the incidence of gefitinib-induced ILD in Japanese patients was higher than the incidence found in our study; the incidence in our study was similar to values reported in worldwide populations. Forsythe and Faulkner [24] suggest that the reason for the observed difference in susceptibility to ILD is related to population or environmental differences or differences in diagnostic or clinical practice. A higher risk of ILD has been noted in Japan than elsewhere with other medications [25]. In fact, the frequency of coincidence with interstitial pneumonitis before gefitinib treatment was much higher $(5.0 \%-13.6 \%)$ [13-17] than that observed in our Korean population $(1.6 \%)$. Of note, comorbid interstitial pneumonitis was found to be a major risk factor for gefitinib-induced ILD in many Japanese studies (Table 4).

Gefitinib-induced ILD usually occurs during the first 3 months of treatment; the range to onset is 24 to 42 days [1]. In our study, the median time to development of ILD was 29 days, and $80.0 \%$ of ILD cases presented within the first 8 weeks of starting gefitinib treatment (Fig. 2). The main manifestations of gefitinib-induced ILD were dyspnea (100.0\%) and cough $(60.0 \%)$, sequentially, while only two patients $(13.3 \%)$ presented with fever, a commonly recognized sign of infectious pneumonia.

The prognosis for gefitinib-induced ILD was consistent with other studies (Table 4). In the present study, among patients diagnosed with ILD, six patients had an ILD related death (mortality, 40.0\%). Treatment of gefitinib-induced ILD is largely supportive, including supplemental oxygen, empirical antibiotics and mechanical ventilation. Immediate discontinuation of the drug is strongly recommended and systemic corticosteroids are usually prescribed, although no controlled trials have been conducted to evaluate their efficacy [5].

We investigated the association between clinical factors at the time of onset and fatality from gefitinib-induced ILD. In this study, the treatment for gefitinib-induced ILD was not significantly different between the fatal and non-fatal groups. When ILD was suspected clinically, gefitinib was discontinued immediately in all patients. The time interval from onset of symptoms to cessation of gefitinib was similar between groups. Among the 15 patients who developed ILD, 12 
patients $(80.0 \%)$ were treated with corticosteroids. The median dose of corticosteroids at the time of onset of ILD, treatment duration and the time interval from ILD onset to administration of corticosteroids were not significantly associated with the prognosis of ILD. No patient was rechallenged with gefitinib after recovery from ILD. In univariate analysis, patients with fatal ILD were more likely to develop ILD within a shorter interval, to have lower $\mathrm{SpO}_{2}$ and lower serum albumin compared to those with non-fatal ILD. Although not confirmed by multivariate analysis, due to small sample size, ILD with abrupt onset after gefitinib treatment and severe pneumonitis requiring high $\mathrm{O}_{2}$ demand apparently has a poor prognosis despite appropriate treatment. Also lower albumin level might be a prognostic factor as well as a predictive factor. Further investigation of possible prognostic factors, including comorbidities, is warranted.

This is the first study that evaluated predictive factors for gefitinib-induced ILD and examined prognostic factors for ILD with the same data set in a large scale of Korean patients treated with gefitinib. However, this study had several limitations. Our study was conducted retrospectively. Another concern was misdiagnosis of ILD, but we believe that the independent review of clinical data by investigators minimized this problem. The diagnosis of ILD is a critical component of this study. It was based on CT findings and clinical characteristics, and biopsies—generally considered the gold standard for ILD diagnosis-were not performed in all cases. This same diagnostic problem was reported in a large prospective study [9]. Nevertheless the clinical features of gefitinib-induced ILD found in our study were similar to those previously reported.

\section{Conclusion}

In summary, the incidence of gefitinib-induced ILD in Korean NSCLC patients was similar to that of worldwide reports but lower than values reported for Japanese population. A lower serum albumin level $(\leq 3.0 \mathrm{~g} / \mathrm{dL})$ at baseline was the only predictive factor for gefitinib-induced ILD. ILD is a serious adverse effect and clinicians should give attention to the possibility of gefitinib-induced ILD, particularly among patients with a lower serum albumin level.

\section{Conflicts of Interest}

Conflict of interest relevant to this article was not reported.

\section{References}

1. Cohen MH, Williams GA, Sridhara R, Chen G, Pazdur R. FDA drug approval summary: gefitinib (ZD1839) (Iressa) tablets. Oncologist. 2003;8:303-6.

2. Mok TS, Wu YL, Thongprasert S, Yang CH, Chu DT, Saijo N, et al. Gefitinib or carboplatin-paclitaxel in pulmonary adenocarcinoma. N Engl J Med. 2009;361:947-57.

3. Maemondo M, Inoue A, Kobayashi K, Sugawara S, Oizumi S, Isobe $\mathrm{H}$, et al. Gefitinib or chemotherapy for non-small-cell lung cancer with mutated EGFR. N Engl J Med. 2010;362:2380-8.

4. Inoue A, Saijo Y, Maemondo M, Gomi K, Tokue Y, Kimura Y, et al. Severe acute interstitial pneumonia and gefitinib. Lancet. 2003;361:137-9.

5. Min JH, Lee HY, Lim H, Ahn MJ, Park K, Chung MP, et al. Drug-induced interstitial lung disease in tyrosine kinase inhibitor therapy for non-small cell lung cancer: a review on current insight. Cancer Chemother Pharmacol. 2011;68: 1099-109.

6. Han JY, Park K, Kim SW, Lee DH, Kim HY, Kim HT, et al. First-SIGNAL: first-line single-agent iressa versus gemcitabine and cisplatin trial in never-smokers with adenocarcinoma of the lung. J Clin Oncol. 2012;30:1122-8.

7. Lee DH, Park K, Kim JH, Lee JS, Shin SW, Kang JH, et al. Ran- domized Phase III trial of gefitinib versus docetaxel in nonsmall cell lung cancer patients who have previously received platinum-based chemotherapy. Clin Cancer Res. 2010;16: 1307-14.

8. Sun JM, Lee KH, Kim SW, Lee DH, Min YJ, Yun HJ, et al. Gefitinib versus pemetrexed as second-line treatment in patients with nonsmall cell lung cancer previously treated with platinum-based chemotherapy (KCSG-LU08-01): an open-label, phase 3 trial. Cancer. 2012;118:6234-42.

9. Kudoh S, Kato H, Nishiwaki Y, Fukuoka M, Nakata K, Ichinose $Y$, et al. Interstitial lung disease in Japanese patients with lung cancer: a cohort and nested case-control study. Am J Respir Crit Care Med. 2008;177:1348-57.

10. Keam B, Kim DW, Park JH, Lee JO, Kim TM, Lee SH, et al. How molecular understanding affects to prescribing patterns and clinical outcome of gefitinib in non-small cell lung cancer? 10 Year experience of single institution. Cancer Res Treat. 2013;45:178-85.

11. Vahid B, Marik PE. Pulmonary complications of novel antineoplastic agents for solid tumors. Chest. 2008;133:528-38.

12. Kang HJ, Park JS, Kim DW, Lee J, Jeong YJ, Choi SM, et al. Adverse pulmonary reactions associated with the use of mon- 
oclonal antibodies in cancer patients. Respir Med. 2012;106: 443-50.

13. Ando M, Okamoto I, Yamamoto N, Takeda K, Tamura K, Seto $\mathrm{T}$, et al. Predictive factors for interstitial lung disease, antitumor response, and survival in non-small-cell lung cancer patients treated with gefitinib. J Clin Oncol. 2006;24:2549-56.

14. Takano T, Ohe Y, Kusumoto M, Tateishi U, Yamamoto S, Nokihara $\mathrm{H}$, et al. Risk factors for interstitial lung disease and predictive factors for tumor response in patients with advanced non-small cell lung cancer treated with gefitinib. Lung Cancer. 2004;45:93-104.

15. Hotta K, Kiura K, Tabata M, Harita S, Gemba K, Yonei T, et al. Interstitial lung disease in Japanese patients with non-small cell lung cancer receiving gefitinib: an analysis of risk factors and treatment outcomes in Okayama Lung Cancer Study Group. Cancer J. 2005;11:417-24.

16. Nakagawa M, Nishimura T, Teramukai S, Tada H, Tanaka F, Yanagihara $\mathrm{K}$, et al. Interstitial lung disease in gefitinib-treated Japanese patients with non-small cell lung cancer: a retrospective analysis: JMTO LC03-02. BMC Res Notes. 2009;2:157.

17. Hotta K, Kiura K, Takigawa N, Yoshioka H, Harita S, Kuyama $S$, et al. Comparison of the incidence and pattern of interstitial lung disease during erlotinib and gefitinib treatment in Japanese Patients with non-small cell lung cancer: the Okayama Lung Cancer Study Group experience. J Thorac Oncol. 2010;5: 179-84.

18. Akamatsu H, Inoue A, Mitsudomi T, Kobayashi K, Nakagawa $\mathrm{K}$, Mori $\mathrm{K}$, et al. Interstitial lung disease associated with gefitinib in Japanese patients with EGFR-mutated non-small-cell lung cancer: combined analysis of two Phase III trials (NEJ 002 and WJTOG 3405). Jpn J Clin Oncol. 2013;43:664-8.

19. Chang SC, Chang CY, Chang SJ, Yuan MK, Lai YC, Liu YC, et al. Gefitinib-related interstitial lung disease in Taiwanese patients with non-small-cell lung cancer. Clin Lung Cancer. 2013;14:55-61.

20. Suzuki H, Aoshiba K, Yokohori N, Nagai A. Epidermal growth factor receptor tyrosine kinase inhibition augments a murine model of pulmonary fibrosis. Cancer Res. 2003;63: 5054-9.

21. Lateef O, Shakoor N, Balk RA. Methotrexate pulmonary toxicity. Expert Opin Drug Saf. 2005;4:723-30.

22. Li J, Brahmer J, Messersmith W, Hidalgo M, Baker SD. Binding of gefitinib, an inhibitor of epidermal growth factor receptortyrosine kinase, to plasma proteins and blood cells: in vitro and in cancer patients. Invest New Drugs. 2006;24:291-7.

23. Ter Heine R, Van den Bosch RT, Schaefer-Prokop CM, Lankheet NA, Beijnen JH, Staaks GH, et al. Fatal interstitial lung disease associated with high erlotinib and metabolite levels: a case report and a review of the literature. Lung Cancer. 2012; 75:391-7.

24. Forsythe B, Faulkner K. Overview of the tolerability of gefitinib (IRESSA) monotherapy : clinical experience in non-smallcell lung cancer. Drug Saf. 2004;27:1081-92.

25. Koo LC, Clark JA, Quesenberry CP, Higenbottam T, Nyberg F, Wolf MK, et al. National differences in reporting 'pneumonia' and 'pneumonia interstitial': an analysis of the WHO International Drug Monitoring Database on 15 drugs in nine countries for seven pulmonary conditions. Pharmacoepidemiol Drug Saf. 2005;14:775-87. 